07,01

\title{
Исследование механизма низкочастотной дискретной акустической эмиссии в ходе прерывистой ползучести алюминиевого сплава
}

\author{
(C) А.А. Шибков, М.А. Желтов, М.Ф. Гасанов, А.Е. Золотов \\ Тамбовский государственный университет им. Г.Р. Державина, \\ Тамбов, Россия \\ E-mail: shibkov@tsu.tmb.ru
}

(Поступила в Редакцию 10 мая 2017 г.)

Исследована корреляция между динамикой деформационных полос и дискретной акустической эмиссией в ходе прерывистой ползучести сплава АМг6 с помощью высокоскоростной видеосъемки с временны́м разрешением до $50 \mu \mathrm{s}$. Триггером макроскопической деформационной ступени на кривой ползучести является зарождение и расширение первичной полосы деформации, которая генерирует характерный сигнал акустической эмиссии длительностью порядка нескольких миллисекунд. Результаты подтверждают механизм генерирования сигнала акустической эмиссии, связанный с кооперативным выходом дислокаций на внешнюю поверхность образца.

Работа выполнена при финансовой поддержке Российского научного фонда (проект № 15-12-00035).

DOI: 10.21883/FTT.2017.12.45232.156

\section{1. Введение}

Как известно, пластическая деформация твердых тел происходит прерывисто и неоднородно на различных масштабных уровнях. На макроскопическом уровне прерывистая пластическая деформация проявляется как повторяющиеся скачки напряжения при деформировании с заданной скоростью $\dot{\varepsilon}_{0}=$ const в жесткой испытательной машине [эффект Портевена-Ле Шателье (ПЛШ)] [1], либо как деформационные ступени при нагружении с постоянной скоростью $\dot{\sigma}_{0}=$ const в мягкой испытательной машине (эффект Савара-Массона [2]), либо как деформационные „взрывы“ при испытаниях на ползучесть (эффект „лестницы“ [3]). Последнее явление, обычно называемое прерывистой ползучестью, проявляется в виде резких ступеней амплитудой от 0.1 до 6\% и более на первой и второй стадиях ползучести в поликристаллических сплавах системы $\mathrm{Ni}-\mathrm{Cr}$ [4-6], аустенитных сталях [7-9] и алюминиевых сплавах [10-12].

Деформационные ступени и скачки напряжения на кривых растяжения сопровождаются локализацией пластической деформации в полосах макролокализованной деформации $[12,13]$. Согласно общепринятой точке зрения эти пластические неустойчивости обусловлены динамическим деформационным старением, т.е. динамическим взаимодействием подвижных дислокаций с диффундирующими атомами примеси [14]. Прерывистое пластическое течение и формирование деформационных полос воздействует на многие свойства материалов: оно уменьшает пластичность металлов, коэффициент скоростной чувствительности и напряжение разрушения. Потеря пластичности, вызванная локализацией деформации, может вызвать преждевременное разрушение конструкционного материала под нагрузкой. Поэтому мониторинг деформационных полос является важной проблемой с научной и практической точек зрения. Обстоятельный обзор экспериментальных методов исследования динамики деформационных полос в условиях эффекта ПЛШ представлен в работе [15], там подчеркивается, что метод акустической эмиссии (АЭ) имеет преимущество по сравнению с другими методами для измерения количества событий, обусловленных прерывистым пластическим течением. Кроме того, непрерывный акустический мониторинг дислокационных лавин несет информацию об их динамике во временном интервале $\sim 1 \mu \mathrm{s}-1 \mathrm{~ms}$ в условиях эффекта ПЛШ [16-24].

В работе [25] отмечается, что локализация пластической деформации должна увеличивать низкочастотные компоненты в спектре АЭ из-за роста корреляции между прыжками дислокаций в ходе их термоактивированного движения в твердом растворе, например, из-за лавинообразного открепления дислокаций от примесных атмосфер. Поэтому сдвиг спектра АЭ в низкочастотную область является индикатором локализации деформации на более высоком масштабном уровне, что экспериментально подтверждено в работах [19,26,27]. В настоящей работе представлены экспериментальные результаты in situ исследования корреляции между динамикой деформационных полос и низкочастотным (в полосе частот $10-1000 \mathrm{~Hz}$ ) акустическим откликом в ходе прерывистой ползучести алюминий-магниевого сплава.

\section{2. Методика}

Материалом исследования являлся промышленный алюминий-магниевый сплав АМг6 (6.15 wt\% $\mathrm{Mg}$, $0.65 \mathrm{wt} \% \mathrm{Mn}, 0.25 \mathrm{wt} \% \mathrm{Si}, 0.21$ wt.\% Fe). Плоские образцы в форме двусторонних лопаток с размером рабочей части $6 \times 3 \times 0.5 \mathrm{~mm}$ вырезали из холоднокатаной 
полосы вдоль направления прокатки. Перед испытанием образцы отжигали при $450^{\circ} \mathrm{C}$ в течение $1 \mathrm{~h}$ с последующей закалкой на воздухе. Такая термообработка давала в результате микроструктуру со средним размером зерна $\sim 10 \mu \mathrm{m}$. Подробные исследования исходной структуры сплава представлены в работе [28].

Для изучения прерывистой ползучести использовали комплекс in situ методов [29] на базе мягкой деформационной машины, специально разработанной для исследования неустойчивой деформации металлов. Мягкая машина представляет собой рычажное устройство, нагружаемое наливанием воды с заданным расходом в сосуд, укрепленный на конце рычага. Данная машина способна производить растяжение металлических образцов с постоянной скоростью возрастания нагрузки, а также в режиме ползучести. Испытание на ползучесть выполняли при комнатной температуре. Перед испытанием образцы состаривали при $20^{\circ} \mathrm{C}$ в течение двух суток для стабилизации структуры.

Силовой отклик измеряли с помощью датчика усилия Zemik A3-C3-100kg-3V с чувствительностью $1.5 \mu \mathrm{V} / N$. Для измерения деформации образца использовали оптический лазерный триангуляционный датчик смещения (Riftec) с точностью $1.5 \mu \mathrm{m}$ в полосе частот $0-2 \mathrm{kHz}$. Данные измерения нагрузки и деформации записывали со скоростью $2 \mathrm{kHz}$. Синхронно с измерением деформации и усилия вели видеосъемку поверхности с помощью скоростной цифровой видеокамеры FASTCAM Mini UX50/100 (Photron), которую использовали для оптического мониторинга со скоростью до $20000 \mathrm{frames} / \mathrm{s}$ процессов образования и распространения деформационных полос. Обработка данных видеосъемки состояла в вычитании с помощью компьютерной программы последовательных кадров видеофильма [30].

Для исследования акустического отклика на прерывистую ползучесть образца сплава АМг6 использовали небольшой (диаметром $6 \mathrm{~mm}$ ) акустический датчик, выполненный на основе титаната бария, который укрепляли через слой масла на неподвижной лопатке образца, связанной с базой (станиной испытательной машины). Канал регистрации сигнала АЭ состоял из широкополосного высокоомного предусилителя $\left(R_{i n}=10^{12} \Omega\right.$, $C_{\text {in }}=20 \mathrm{pF}$, полоса пропускания $\left.1-10^{6} \mathrm{~Hz}\right)$, коммутатора, многоканального аналого-цифрового преобразователя (АЦП) и компьютера. Сигналы АЭ, датчиков положения, усилия и сигнал скоростной видеокамеры в виде меандра на частоте съемки синхронно записывали с помощью четырех каналов АЦП с тактовой частотой $100 \mathrm{kHz}$ на канал.

\section{3. Результаты и обсуждение}

На рис. 1 представлен типичный пример синхронной записи данных измерения деформации, напряжения и сигнала акустической эмиссии в ходе спонтанного
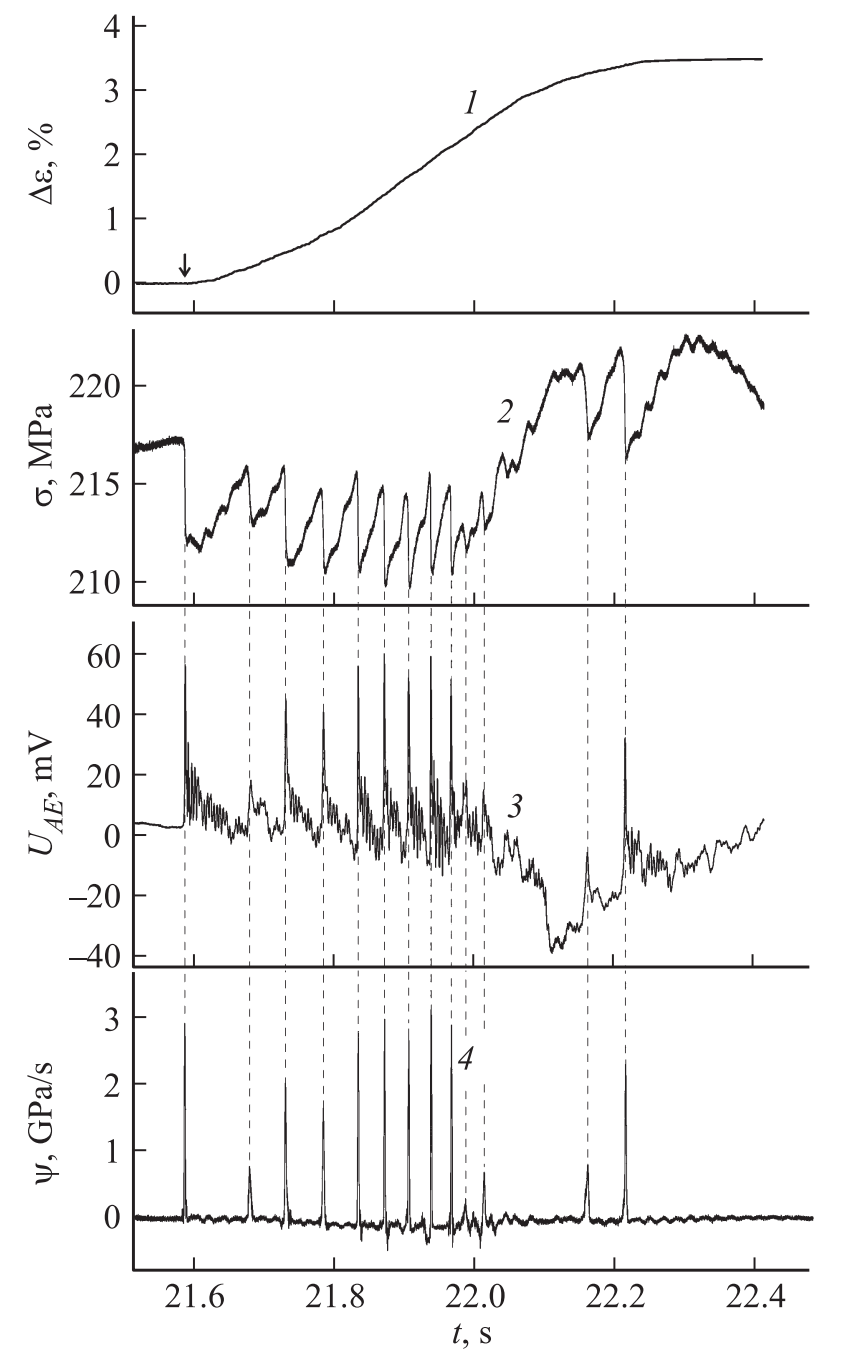

Рис. 1. Макроскопическая ступень $\Delta \varepsilon(1)$ на кривой ползучести при напряжении $\sigma_{0}=217 \mathrm{MPa}$, силовой отклик $\sigma(2)$, сигнал акустической эмиссии $U_{A E}(3)$ и функция $\psi(4)-$ Временна́я зависимость абсолютной величины производной по времени силового отклика. Стрелкой отмечен момент зарождения первичной полосы деформации.

зарождения и развития деформационной ступени амплитудой $\sim 4 \%$ на кривой ползучести при напряжении $\sigma_{0}=217 \mathrm{MPa}$, значительно превышающем условный предел текучести $\sigma_{0.2} \approx 160 \mathrm{MPa} \mathrm{в} \mathrm{сплаве} \mathrm{АМг6.}$ Форма деформационной ступени, т. е. временна́я зависимость приращения деформации $\Delta \varepsilon(t)$ на фронте ступени близка к сигмоидальной логистической кривой с характерным временем нарастания (длительностью фронта) $~ 600 \mathrm{~ms}$ (рис. 1, кривая 1). Силовой отклик (рис. 2, кривая 2) содержит более десятка скачков напряжения амплитудой $\sim 3-10 \mathrm{MPa}$ и длительностью переднего фронта $\sim 1-3$ ms. Такой прерывистый силовой отклик, аналогичный эффекту ПЛШ, связан с инерционностью механической системы „машина-образец“ $[12,31,32]$.

Как было установлено в работе [12], каждый скачок напряжения связан с появлением, как правило, одной 
деформационной полосы, которая имеет форму расширяющейся шейки. Эволюция каждой полосы характеризуется двумя последовательными стадиями - быстрой и медленной. Быстрая стадия длительностью $\sim 1-3 \mathrm{~ms}$ сопровождается резкой разгрузкой механической системы амплитудой до $\sim 10 \mathrm{MPa,} \mathrm{в} \mathrm{то} \mathrm{время} \mathrm{как} \mathrm{медленная}$ стадия расширения длительностью $\sim 10-100 \mathrm{~ms}$ сопровождается непрерывным восстановлением напряжения почти до исходного значения.

Как видно из рис. 1, каждый скачок напряжения сопровождается всплеском сигнала АЭ, который представляет собой последовательность затухающих колебаний с временем затухания $\sim 30 \mathrm{~ms}$. Первое акустическое колебание в структуре всплеска АЭ происходит одновременно с резкой разгрузкой механической системы, а следовательно, с начальной быстрой стадией эволюции деформационной полосы, которая включает процессы зарождения и быстрого расширения новой полосы продолжительностью $\sim 1-3 \mathrm{~ms}$. Последующие затухающие колебания в структуре всплеска АЭ происходят одновременно с непрерывным восстановлением напряжения,
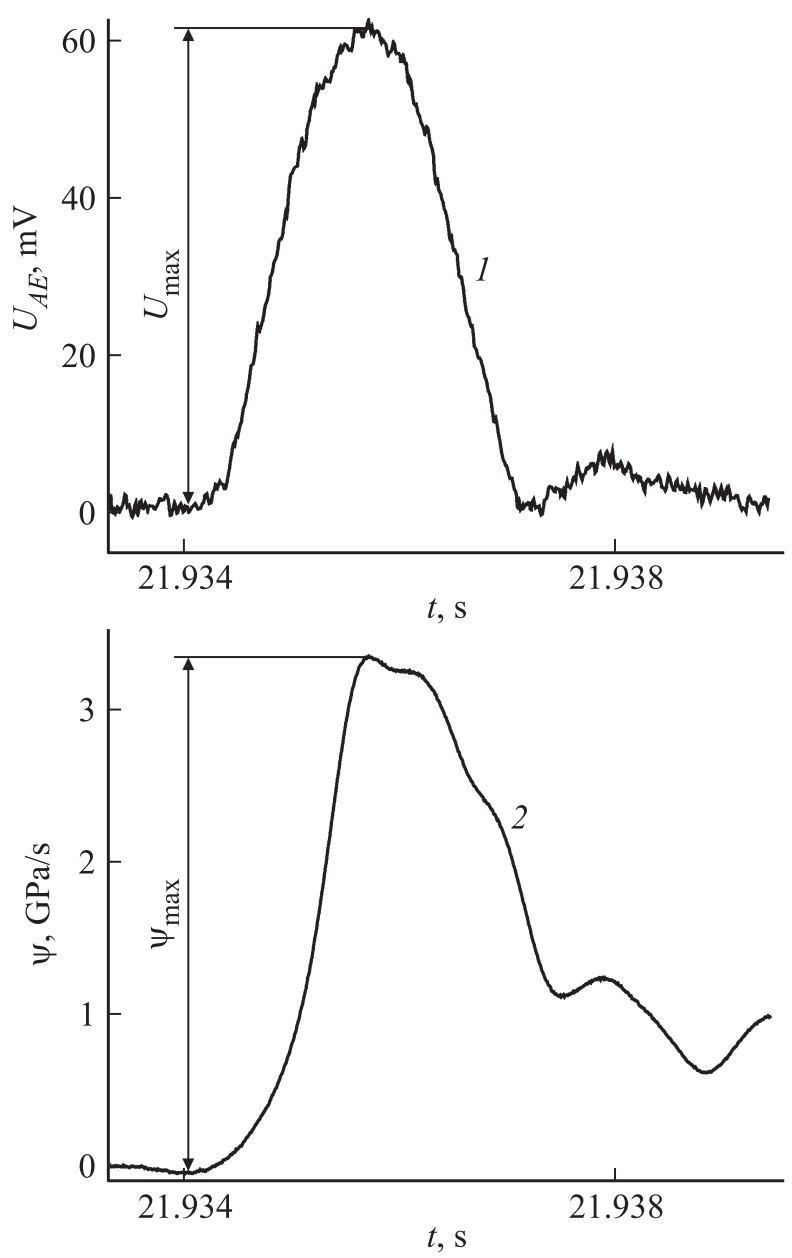

Pис. 2. Типичный пример первого колебания амплитудой $U_{\max }$ всплеска АЭ (1), вызванного формированием деформационной полосы, и соответствующий пик функции $\psi(2)$ амплитудой $\psi_{\max }$.

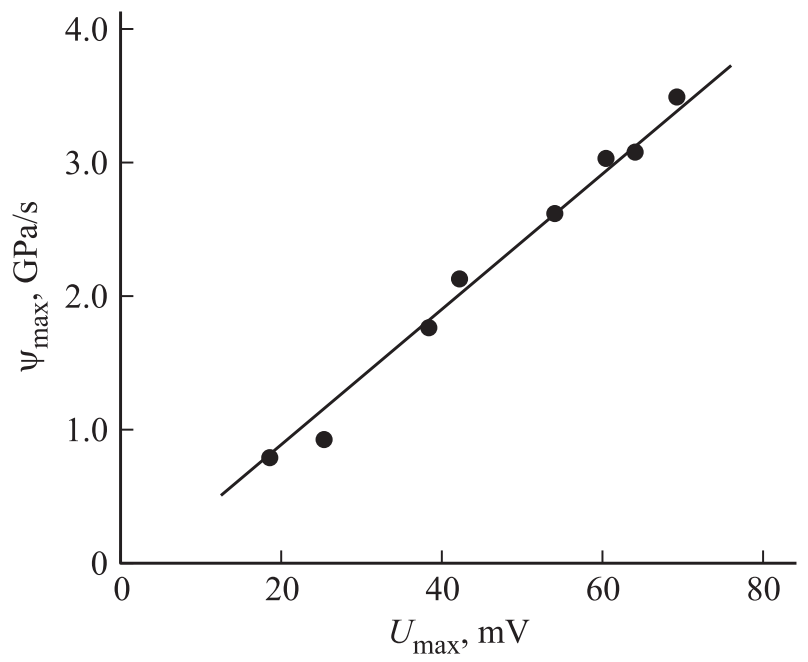

Рис. 3. Зависимость $\psi_{\max }\left(U_{\max }\right)$. Коэффициент корреляции с линейной аппроксимацией $k=0.9985$.

которое связано с медленной стадией (без каких-либо нерегулярностей) расширения деформационной полосы [12]. Поэтому затухающие колебания после первого колебания с максимальной амплитудой, в структуре всплеска АЭ (рис. 1, кривая 3) не связаны с какими-либо релаксационными процессами в деформируемом материале, а связаны, скорее, с возбуждением собственных колебаний механической системы „машина-образец“. Действительно, основная частота затухающих колебаний в сигнале АЭ $(\sim 300 \mathrm{~Hz})$, согласно данным баллистических испытаний, совпадает с собственной частотой испытательной машины при напряжении растяжения $\sim 200 \mathrm{MPa}$. Таким образом, можно заключить, только первое акустическое колебание в структуре всплеска АЭ несет информацию о динамике деформационной полосы, а именно о зарождении и начальной быстрой стадии эволюции полосы.

Рассмотрим другой временной ряд, который помимо сигнала АЭ отражает пластическую неустойчивость на макроуровне: абсолютное значение производной по времени силового отклика $\psi(t)=|d \sigma(t) / d t|$. Этот временной ряд использовали для характеризации скачков пластического течения в сплавах системы $\mathrm{Al}-\mathrm{Mg}$ в условиях эффекта ПЛШ [33-37]. Кривые 3 и 4 на рис. 1 демонстрируют корреляцию между сигналом АЭ $U_{A E}(t)$ и функцией $\psi(t)$. Как видно из рис. 2 , форма первой осцилляции в сигнале АЭ (кривая 1) имеет сходство с формой импульса функции $\psi(t)$ (кривая 2), наблюдаемой в ходе начальной быстрой стадии эволюции полосы деформации. Рис. 3 демонстрирует приблизительно линейную зависимость амплитуды $\psi_{\max }$ пика функции $\psi(t)$ от амплитуды $U_{\max }$ первого колебания в сигнале АЭ со сравнительно высоким коэффициентом корреляции $(k=0.9985)$. Это означает, что сигнал АЭ, вызванный зарождением и быстрой стадией эволюции деформационной полосы, дает информацию о скорости 
I
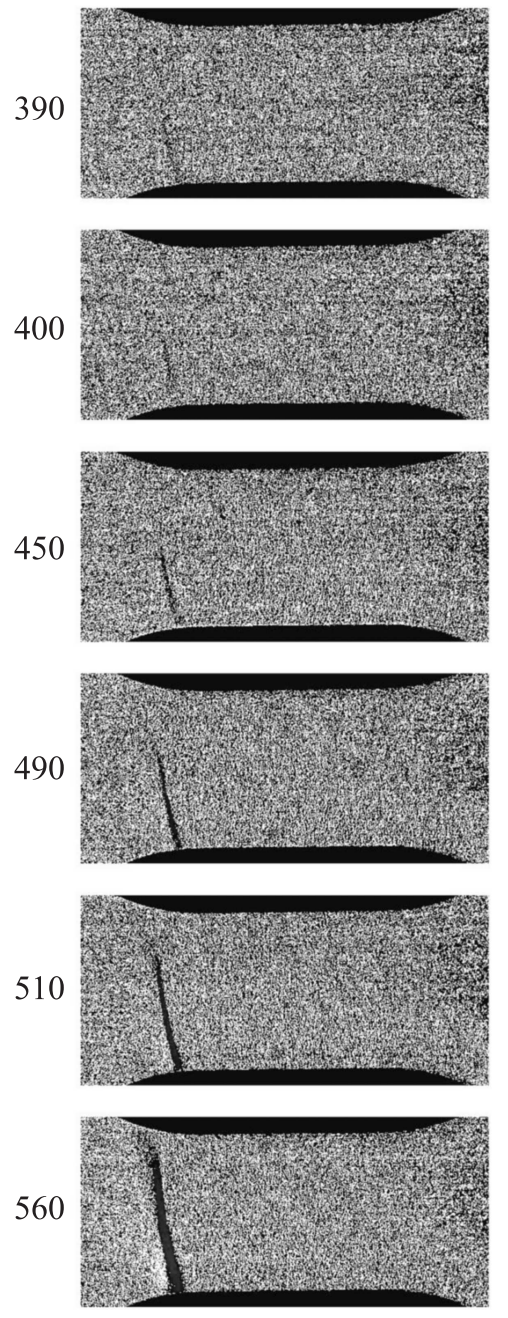

II

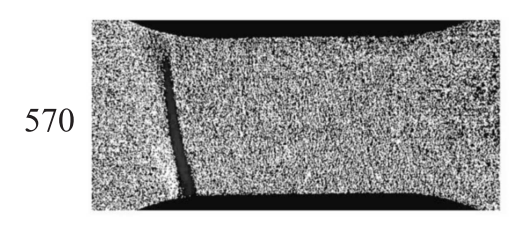

580

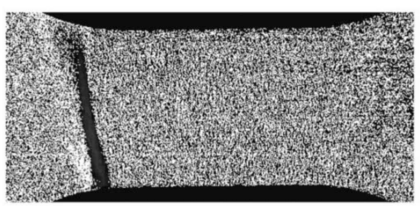

590

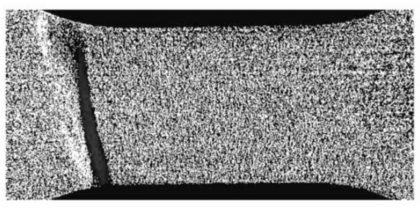

600

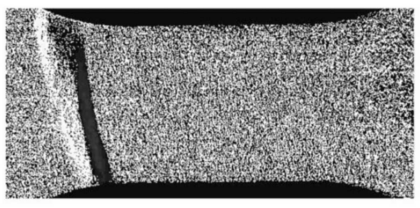

610

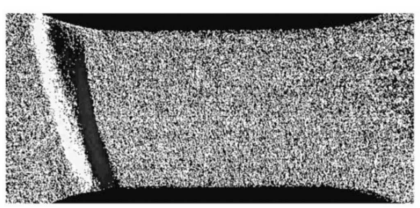

620

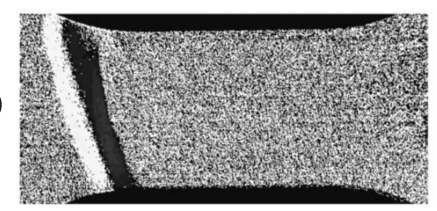

III

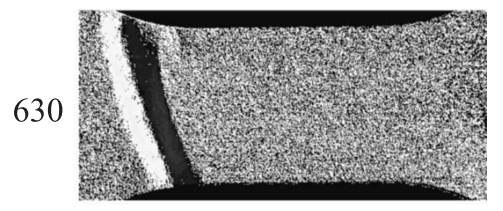

640

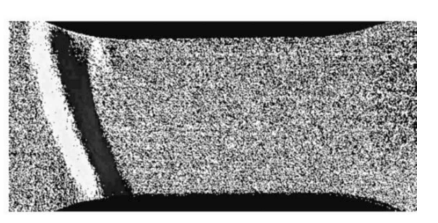

650

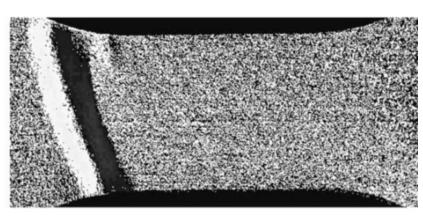

670

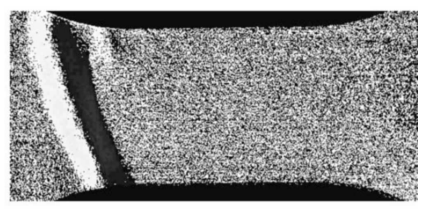

680

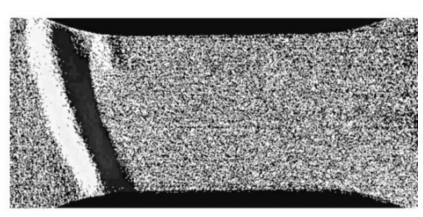

690

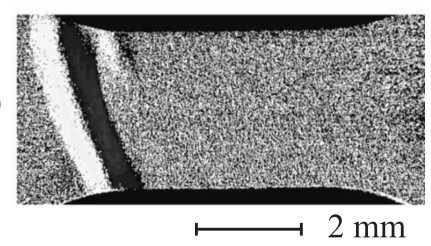

Рис. 4. Результаты компьютерной обработки данных видеосьемки роста первичной полосы деформации. Римскими цифрами отмечены основные стадии эволюции полосы: I - стадия поперечного роста „зародыша“ полосы - незавершенной полосы локализованного сдвига, II - стадия резкого расширения полосы, III - стадия медленного расширения полосы. Числами отмечены номера кадров. Скорость видеосъемки 20000 frames/s (временной интервал между кадрами $50 \mu \mathrm{s}$ ).

изменения силового отклика. Следовательно, значение измерения акустической эмиссии в условиях прерывистой ползучести состоит в том, что метод АЭ дает в реальном времени информацию о скачках разгрузки, пиках функции $\psi(t)$ и количестве деформационных полос без использования датчика усилия и видеокамеры, например, в условиях эксплуатации конструкционного материала.

Согласно данным работы [12], основным механизмом развития макроскопической деформационной ступени на кривой ползучести является размножение деформационных полос, когда за исключением первичной полосы каждая новая полоса деформации зарождается на границе предшествующей полосы. Первичная полоса зарождается спонтанно в случайной позиции на рабочей длине образца, является триггером развития деформационной ступени.
Рассмотрим более детально раннюю стадию эволюции первичной полосы для исследования особенностей корреляции между зарождением локализации пластической деформации и характеристиками сигнала АЭ. На рис. 4 представлены данные видеозаписи начальной стадии эволюции первичной полосы со скоростью съемки $20000 \mathrm{frames} / \mathrm{s}$, синхронизированные с сигналом АЭ. Как видно из рисунка, пластическая деформация локализуется сначала в виде зародыша деформационной полосы, который возникает на одном из ребер образца (кадр I). Этот зародыш полосы в форме узкого клина деформированного материала затем растет в объем образца под некоторым углом к оси растяжения в течение 3-10 ms, что качественно согласуется с ростом зародыша полосы ПЛШ типа В в сплавах систем $\mathrm{Al}-\mathrm{Cu}$ и $\mathrm{Al}-\mathrm{Mg}$, деформируемых в жесткой испытательной машине [38-41]. 


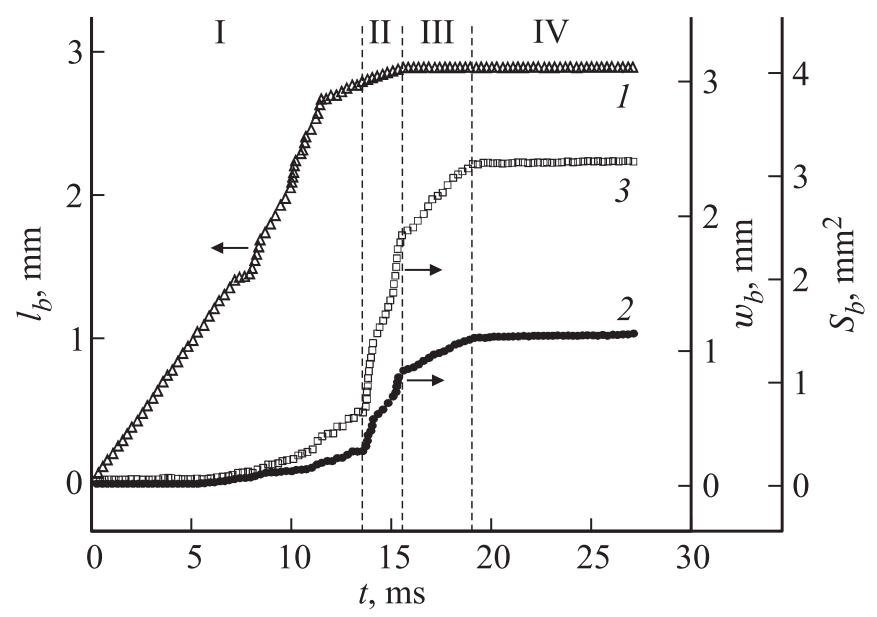

Рис. 5. Временны́е зависимости длины $l_{b}(1)$, ширины $w_{b}(2)$ и площади $S_{b}(3)$ первичной полосы деформации - триггера развития макроскопической ступени на кривой ползучести сплава АМг6. Минимальный временной интервал между экспериментальными точками $50 \mu \mathrm{s}$.

В момент времени, когда зародыш полосы пересекает все поперечное сечение и выходит на противоположную поверхность образца, формирование деформационной полосы заканчивается, и начинается ее расширение. На рис. 5 представлены кинетические кривые, характеризующие рост первичной деформационной полосы временны́е зависимости длины $l_{b}(1)$, ширины $w_{b}(2)$ и площади $S_{b}(3)$ полосы. Как показывает анализ корреляций этих кривых с силовым и акустическим откликом, наибольший коэффициент корреляции наблюдается для временно́й зависимости площади полосы $S_{b}(t)$ с соответствующими откликами. По скорости роста площади полосы в кинетике и морфологии полосы можно выделить, по крайней мере, четыре основные временны́е стадии (рис. 4): стадия I поперечного роста зародыша полосы со скоростью вершины $v_{t}$ до $\sim 1 \mathrm{~m} / \mathrm{s}$ (кадры 390-570), которая заканчивается выходом полосы на противоположную от источника поверхность образца (кадр 570), на этой стадии формируется завершенная (пересекающая все поперечное сечение) полоса локализованного сдвига; стадия II лавинообразного расширения полосы со скоростью $v_{w}$ до $30 \mathrm{~cm} / \mathrm{s}$ (кадры 570-610), когда скорость роста площади полосы достигает максимального значения $\left(\approx 1 \mathrm{~mm}^{2} / \mathrm{ms}\right)$, на этой стадии завершения полоса локализованного сдвига трансформируется в расширяющуюся шейку (рис. 2 в работе [42]), стадия III медленного непрерывного расширения деформационной полосы и стадия IV квазистационарного состояния полосы. Можно выделить и более тонкую структуру кинетики полосы, связанную с неравномерным ростом полосы на стадии I и появлением небольшой вторичной полосы-сателлита на правой границе расширяющейся первичной полосы на стадии III (кадры 620-680).
Стадия I роста полосы-зародыша (рис. 6) сопровождается постепенным ростом сигнала АЭ. Резкий рост сигнала АЭ происходит только на стадии II после выхода полосы локализованного сдвига на противоположную поверхность образца и последующего лавинообразного роста площади полосы. На этой стадии развития полосы абсолютные значения всех откликов достигают максимальных значений. Коэффициент корреляции между функциями $S_{b}(t)$ и акустическим сигналом $U_{A E}(t)$ на первых двух стадиях достигает значения $k_{U S}=0.9857$, что несколько выше коэффициента корреляции с силовым откликом $k_{U \sigma}=0.9673$. Таким образом, резкий рост сигнала АЭ происходит только полосе формирования

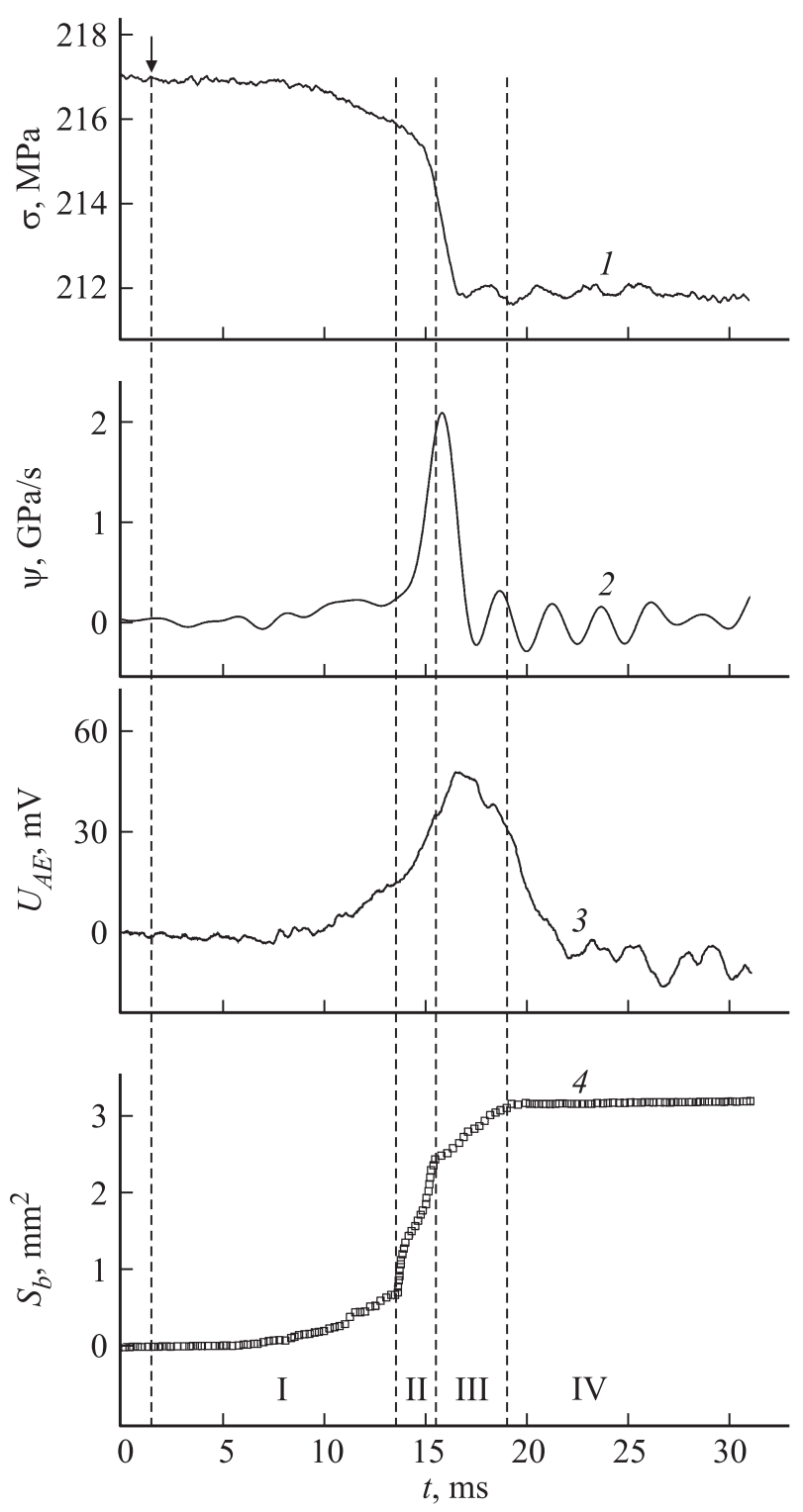

Рис. 6. Временнб́е зависимости напряжения $\sigma(1)$, функции $\psi(2)$, сигнала акустической эмиссии $U_{A E}(3)$ и площади первичной полосы $S_{b}(4)$. Стрелкой отмечен момент зарождения первичной полосы по данным скоростной видеосъемки. Римскими цифрами I-IV отмечены стадии эволюции полосы. 
сквозной полосы (завершенная полоса) в результате движения большого количества дислокаций через все поперечное сечение и их выхода на внешнюю поверхность образца.

Обычное представление об АЭ, сопровождающей прерывистое течение ПЛШ, связывает всплески сигнала АЭ с зарождением деформационных полос $[17,18,20,22]$, в то же время результаты настоящей работы показывают, что зарождение и эволюция полосы деформации генерирует сравнительно слабый сигнал АЭ, а основной вклад в акустический всплеск дает формирование сквозной полосы, которое сопровождается выходом дислокаций на внешнюю поверхность образца. Это наблюдение подтверждает механизм генерирования сигнала АЭ в результате выхода дислокаций на поверхность образца [43].

Таким образом, представленные результаты исследования корреляции между динамикой деформационных полос и сигналами АЭ в ходе прерывистой ползучести АМг6 показывают, что первое колебание длительностью 3-10 ms в структуре всплеска сигнала АЭ связано с формированием первичной полосы деформации, которая является триггером развития макроскопической деформационной ступени длительностью переднего фронта $\sim 0.5 \mathrm{~s}$ в условиях прерывистой ползучести. Поэтому это первое акустическое колебание можно рассматривать как акустический предвестник макроскопической деформационной ступени, который может быть использован для запуска силовых устройств для подавления деформационной неустойчивости, например, для запуска генератора тока для подавления током деформационного скачка и развития деформационных полос [44].

\section{4. Заключение}

Впервые с временны́м разрешением до $50 \mu$ s исследована корреляция между прерывистой ползучестью и дискретной низкочастотной (в полосе частот $10-1000 \mathrm{~Hz}$ ) акустической эмиссией в промышленном сплаве АМг6. Триггером развития деформационной ступени на кривой ползучести является процесс зарождения и быстрого расширения первичной деформационной полосы, который генерирует характерный сигнал АЭ длительностью $\sim 3-10 \mathrm{~ms}$. Предполагается, что наиболее вероятным механизмом генерации акустического сигналапредвестника является формирование первичной сквозной полосы деформации вследствие зарождения и движения большого количества дислокаций через все поперечное сечение и их выход на внешнюю поверхность образца. Обнаруженные корреляции между сигналами АЭ и процессами образования деформационных полос могут составлять научную основу для разработки методов ранней диагностики локализации пластической деформации в сплавах, демонстрирующих прерывистую ползучесть.

\section{Список литературы}

[1] A. Portevin, F.Le Chatelier. C.R. Acad. Sci. Paris 176, 507 (1923).

[2] F. Savart. Ann. Chim. Fhys. 65, 337 (1837).

[3] E.N. Andrade. Proc. Roy Soc. 84, 1 (1910).

[4] R.L. Klueh, J.F. King. Scr. Metall. 13, 205 (1979).

[5] R.L. Klueh, J.F. King. J. Nuclear Mater. 98, 173 (1981).

[6] R.L. Klueh. Mater. Sci. Eng. 54, 65 (1982).

[7] T.L. Silveira, S.N. Monteiro. Metall. Trans. A 10, 1795 (1979).

[8] S.N. Monteiro, T.L. Silveira, I. LeMay. Scr. Metall. 15, 957 (1971).

[9] V.K. Sikka, S.V. David. Metall. Trans. A 12, 883 (1981).

[10] J. Kariya, H. Oikawa, S. Karashina. Trans. Jpn. Inst. Met. 14, 327 (1973)

[11] M. Hamersky, P. Lukac, Z. Trojanova, E. Pink. Mater Sci. Eng. A 148, 7 (1991).

[12] A.A. Shibkov, M.F. Gasanov, M.A. Zheltov, A.E. Zolotov, V.I. Ivolgin. Int. J. Plast. 86, 37 (2016).

[13] K. Chihab, Y. Estrin, L.P. Kubin, J. Vergnol. J. Scr. Metall. 21, 203 (1987)

[14] L.P. Kubin, C. Fressengeas, G. Ananthakrishna. In: Dislocations in solids. F.R.N. Nabarro, M.S. Duesbery. Ed. by Elsevier, Amsterdam (2002). P. 101.

[15] A.J. Yilmaz. Sci. Technol. Adv. Mater. 12, 1 (2011).

[16] F. Chmelik, A. Ziegenbein, H. Neuhauser, P. Lukac. Mater. Sci. Eng. A 324, 200 (2002).

[17] F. Chmelik, F.B. Klose, H. Dierke, J. Sachl, H. Neuhauser, P. Lukac. Mater. Sci. Eng. A 462, 53 (2007).

[18] М.М. Криштал, Д.Л. Мерсон. ФММ 81, 1, 156 (1996).

[19] М.М. Криштал, А.К. Хрусталев, А.А. Разуваев, И.С. Демин. Деформация и разрушение материалов 1, 28 (2008).

[20] M.A. Lebyodkin, T.A. Lebedkina, F. Chmelik, T.T. Lamark, Y. Estrin, C. Fressengeas. J. Weiss. Phys. Rev. B 79, 174114 (2009).

[21] M.A. Lebyodkin, N.P. Kobelev, Y. Bougherira, D. Entemeyer, C. Fressengeas, V.S. Gornakov, T.A. Lebedkina, I.V. Shashkov. Acta Mater. 60, 3729 (2012).

[22] I.V. Shashkov, M.A. Lebyodkin, T.A. Lebedkina. Acta Mater. 60, 6842 (2012).

[23] M.A. Lebyodkin, I.V. Shashkov, T.A. Lebedkina. Phys. Rev. E 88, 042402 (2013).

[24] J. Kumar, R. Sarmah, G. Ananthakrishna. Phys. Rev. B 92, 144109 (2015).

[25] A. Vinogradov, A. Lasarev. Scr. Mater. 66, 745 (2012).

[26] A.V. Vinogradov, V. Patlan, S. Hashimoto. Philos. Mag. 81, 1427 (2001).

[27] A. Lazarev, A. Vinogradov. J. Acoust. Emission 27, 144 (2009).

[28] А.А. Шибков, А.А. Мазилкин, С.Г. Протасова, Д.В. Михлик, А.Е. Золотов, М.А. Желтов, А.В. Шуклинов. Деформация и разрушение материалов 5, 24 (2008).

[29] А.А. Шибков, М.А. Лебедкин, М.А. Желтов, В.В. Скворцов, М.А. Желтов, А.В. Шуклинов. Заводская лаборатория 71, 20 (2005).

[30] А.А. Шибков, А.Е. Золотов, М.А. Желтов. Изв. РАН. Сер. физическая 76, 97 (2012).

[31] А.А. Шибков, А.Е. Золотов, М.А. Желтов, А.А. Денисов, М.Ф. Гасанов. ЖТФ 84, 40 (2014).

[32] А.А. Шибков, А.Е. Золотов, М.А. Желтов, М.Ф. Гасанов, А.А. Денисов. ФТТ 56, 848 (2014). 
[33] M.S. Bharathi, G. Ananthakrishna, C. Fressengeas, L.P. Kubin, M. Lebyodkin. Phys. Rev. Lett. 87, 165508 (2001).

[34] M.S. Bharathi, M. Lebedkin, G. Ananthakrishna, C. Fressengeas, L.P. Kubin. Acta Mater. 50, 2813 (2002).

[35] M.A. Lebyodkin, Y. Estrin. Acta Mater. 53, 3403 (2005).

[36] M.A. Lebyodkin, T.A. Lebedkina. Phys. Rev. E 73, 036114 (2006).

[37] M.A. Lebyodkin, T.A. Lebedkina. Phys. Rev. E 77, 026111 (2008).

[38] W. Tong, H. Tao, N. Zhang, L.G. Hector. Scr. Mater. 53, 87 (2005).

[39] G.F. Xiang, Q.C. Zhang, H.W. Liu, X.P. Wu, X.Y. Ju. Scr. Mater. 56, 721 (2007).

[40] В.В. Горбатенко, В.И. Данилов, Л.Б. Зуев. ЖТФ 87, 372 (2017).

[41] А.А. Шибков, А.Е. Золотов. Актуальные проблемы механики деформируемых твердых тел. Нелинейная динамика неустойчивой пластической деформации металлов. Изд. дом ТГУ им. Г.Р. Державина, Тамбов. (2010). 187 с.

[42] А.А. Шибков, А.Е. Золотов. Письма в ЖЭТФ 90, 412 (2009).

[43] В.Д. Нацик. Письма в ЖЭТФ 8, 198 (1968).

[44] A.A. Shibkov, A.A. Denisov, M.A. Zheltov, A.E. Zolotov, M.F. Gasanov. Mater. Sci. Eng. A 610, 338 (2014). 